\title{
MECHANISM OF THE WETTABILITY OF ALUMINA BY POLYPHOSPHATE GLASSES
}

\author{
A. LEDOUX*, J.Y. DAUPHIN**, G. MESMAQUE***, P. VAST* ${ }^{*}$ \\ * Laboratoire de Chimie Appliquée Université de Sciences et Techniques de Lille, \\ 59655 Villeneuve d'Ascq France \\ ** Ecole Centrale de Lille , 59655 Villeneuve d'Ascq France \\ *** Laboratoire de Mécanique de Lille I U T A Université de Sciences et \\ Techniques de Lille, 59655 Villeneuve d'Ascq France
}

\begin{abstract}
Polyphosphates glasses may be used as a sintering aid for alumina based ceramics composites. The knowledge of the mechanism of the wettability of alumina by melted polyphosphate glasses is an fundamental point for the sinterring control. We show that the wettability on inactive alumina is obtained in two stages .

The first stage consists in a reaction between alumina and phosphorus pentoxyde exhaust from the melted glass bulk. The formation of a thin layer of aluminium phosphate permits, in a second stage, the wettability of the alumina. So the control of wettability needs to adapt the glasses formula to the phosphorus pentoxyde exhaust power in melted phase.
\end{abstract}

\section{INTRODUCTION}

Phosphate glasses present some interest because of their relativity large thermal expansion and low transformation temperature ${ }^{1}$. In a same way the chemical reactivity of the polyphosphate liquid may be modulated by the choice of the cations associated with the phosphate chains 2,3 . These properties indicate their good applicability to different fields such as metal and ceramics seals.

For example, phosphate glasses may be used to join alumina particles to metal or other ceramic substrate to obtain thermal barriers, cermet ${ }^{4}$ for electric applications or coating on alumina bulk for medical applications, like biomaterials for hip prosthesis.

For much of our work we use a soft chemistry route- the coacervation obtained from colloïdal precursors 5 - for the synthesis of polyphosphate glasses. We start from Graham salts which are a commercial sodium polyphosphate glass. This salt, soluble in water, gives a coacervate with the addition of another cation, generally multivalent ions. +To whom all correrspondance should be addressed

$\overline{\text { Received November 3, 1998; Accepted July 3, } 1998}$ 
In a second stage, by heating we obtain phosphate glasses whose the formulation, chain length, and consequently the water quantity as $\mathrm{P}-\mathrm{OH}$ groups can be adjusted ${ }^{6}$. This formulation permit us to adapt the principal thermal properties of glasses ${ }^{7}$ as $\mathrm{Tg}$, Tc, Ts, Tm and C T E to basic needs for use in.

By thermal analysis, the reactivity of alumina with polyphosphate glasse appears to decrease with the water ratio as $\mathrm{P}-\mathrm{OH}$ and the $\mathrm{Al}-\mathrm{OH}$ groups. Nevertheless, polyphosphate glasses present always a very good wettability power on alumina substrate whatever the reactivity of alumina or glasse.

This is the aim of this work which studies the mechanism of this wettability by anhydrous polyphosphate glasses in the system $\mathrm{Na}_{2} \mathrm{O}-\mathrm{CaO}-\mathrm{P}_{2} \mathrm{O}_{5}$.

\section{EXPERIMENTAL PROCEDURE}

The glasses containing both sodium and calcium are obtained by a coacervate route according to Vast et al ${ }^{7}$. The glass sample containing only calcium or sodium is obtained by reaction between orthophosphoric acid an carbonates following, by heating in a platinum dish: 2 hours at $200^{\circ} \mathrm{C}$ and 1 hour at $1100^{\circ} \mathrm{C}^{-1}$.

The wettability by sessile drop is measured in a furnace with a camera and studied by computer.

The Raman microprobes analysis has been caried out with an XY Dilor confocal spectrometer -1990-. The SEM and EDS analysis have been obtained with a JEOL SM $35 \mathrm{C}$ with an ED $S$ microanalyse PGT.

\section{REACTIVITY OF POLYPHOPSHATE GLASSES WITH ALUMINA}

At less than the melting point of glasses, alumina may react essentially by a Brönstedt acid-base reaction; because the phosphate glasses syntheses always induce an acid media by $\mathrm{P}-\mathrm{OH}$ groups formation ${ }^{6,7}$. This kind of reaction may also appear at the crystallization temperature of glasses which give a water exhaust ${ }^{1}$. Recently we have shown that water comming from P-OH groups may be diffused in the solid glass bulk ${ }^{13}$. However the most important reactivity leads to the melting state of glasses. At present the most data concern the reactivity of sodium polyphosphate glasses, such Graham salts, with alumina $8,9,10$. Our results otained in one of our laboratory are incorrect for inactive alumina ${ }^{8,10}$, and we have little data about the activity of alumina used by Berul et al 9 .

Nevertheless, it is well-known that in temperatures above melting point $\left(600-900^{\circ} \mathrm{C}\right.$ in 
accordance with the quantity of sodium ), polyphosphate glass may give an exhaust of $\mathrm{P}_{2} \mathrm{O}_{5}$ allowing for the reaction [3].

$3 \mathrm{PO}_{3}{ }^{-}--\rightarrow \mathrm{PO}_{4}^{---}+\mathrm{P}_{2} \mathrm{O}_{5}$

However, metaphopshate ion may also react as an oxoacid like

$\mathrm{PO}_{3}^{-}+\mathrm{O}^{--}-\rightarrow \mathrm{PO}_{4}^{---}$

and explain a reaction with alumina with the formation of $\mathrm{AlPO}_{4}$.

We, thus, have study also the wettability of alumina such as fused alumina, sapphire (sheet and fiber), and sintered alumina .

\section{Wettability}

Little piece of glass is placed on the alumina substrate. The heating speed is low, around the Tc value (about $3^{\circ} \mathrm{C} /$ minute). The following phenomena can be observed: At the Tc value, sudden crystallization is always accompanied by the formation of outgrowth structures. This outgrowth formation traps the beginning of exhaust of water and is depending of the chains length ${ }^{1}$. Then the glass melts and gives a drop that evolves with time. Initially there is a low wettability, but in following minutes, we suddenly obtain a very good wettability power of the glasse on alumina after the formation of a very thin layer on the alumina surface (fig 1); this phenomenon appears less clearly with fused alumina.
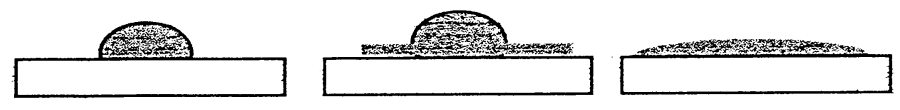

\section{FIGURE 1}

Evolution of a drop of melted polyphosphate glass on alumina ( sapphire or sintered alumina) substrate with time near the melting temperature. The wettability phenomenon presents two steps.

To explain this phenomenon, we have studied the partially wetted (with calcium- sodium glass) sapphire sheet sample by Raman microprobe ${ }^{12}$ and S E M associated with EDS analysis .

The Raman spectra are obtained through the transparent sapphire sheet (figure 2).

Inside the glass bulk $(\gamma)$ we observe the metaphopshate spectra formation of some trimetaphosphate pyrophosphates and orthophosphates species. At the interface $(\beta)$, the importance of these species increases, and at the outside of the glass bulk, we obtain only the alumina spectrum $(\alpha)$. These results may be explained by a reaction - like (2) between alumina and melted glass during the wettability phenomenon, and appears as a 

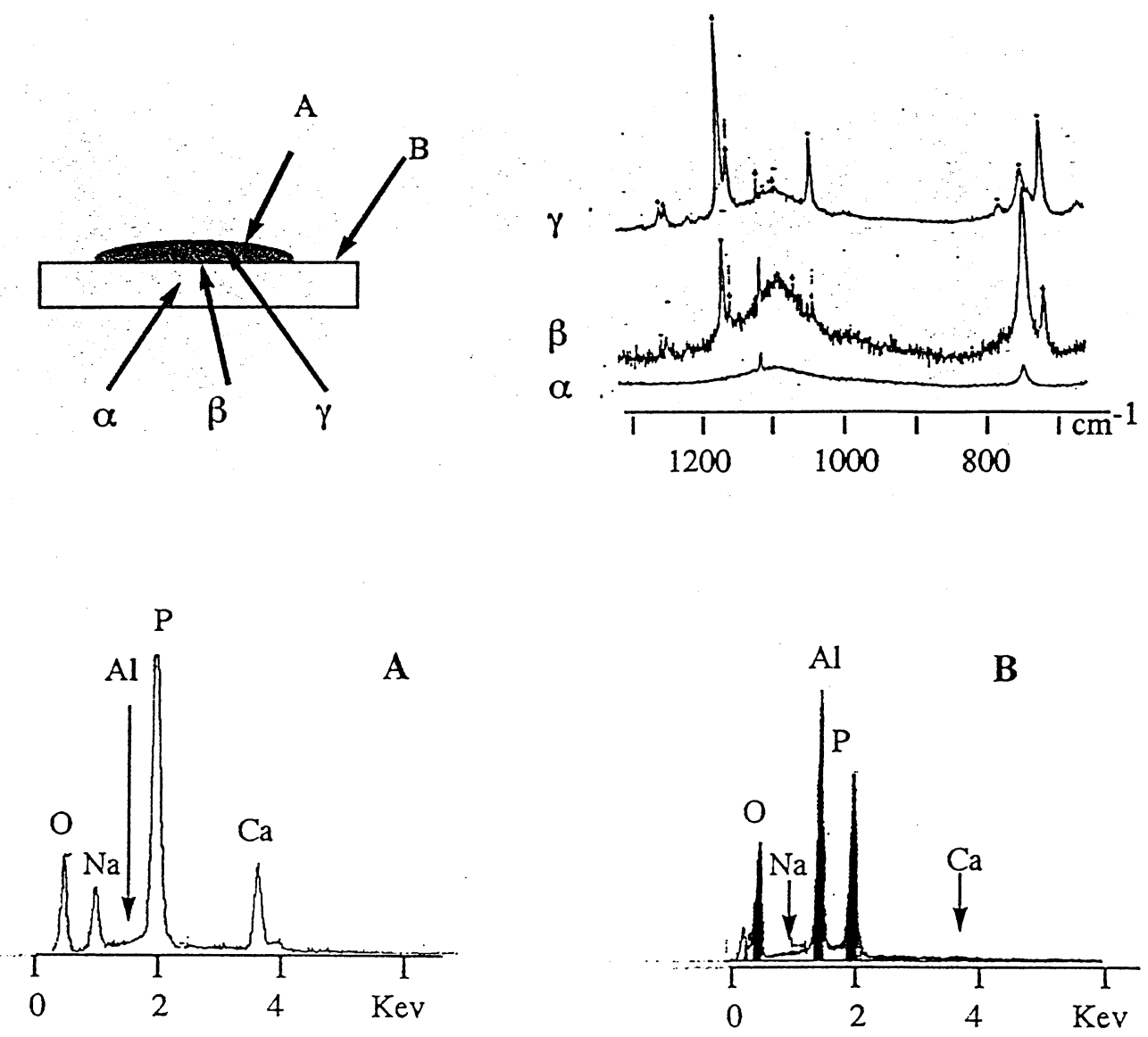

FIGURE 2. Study of a sodium calcium glass drop cooled after wetting a sapphir sheet. In upper Raman microprobe results for the $\alpha, \beta, \gamma$ parts, down EDS results for $A, B$ parts.

result of this wettability.

However, by S E M and EDS analysis on the same sample we can see (figure 2):

-Presence of sodium calcium oxygen and phosphorus without aluminium for the initial glass even near the boundary between glass and alumina without coating.

-Presence only of aluminium, phosphorus and oxygen without sodium and calcium in some areas far of the glass bulk.

In an other experiment with a sheet of sintered alumina, we have been able to quench the sample at the first stage of wettability, as shown in the figure 1. Figure 3 shows, with a magnification, the film which the melted glass of sodium polyphosphate drop leaves on the alumina surface. By ED S (fig3), a similar spectra like the original glass is observed, but also a aluminium presence in little quantity. 

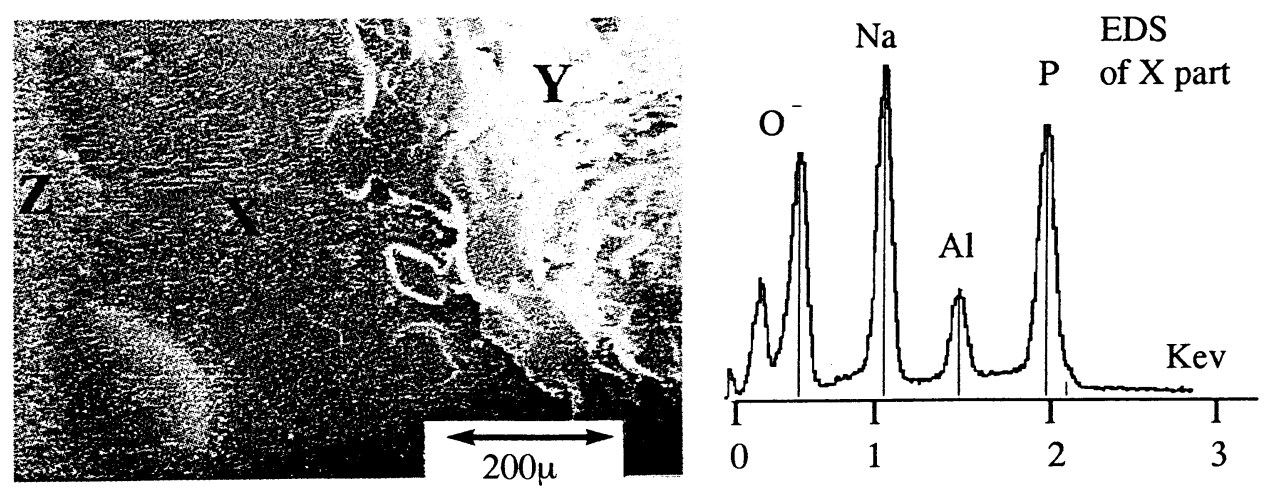

FIGURE 3. A sintered alumina sheet was quenching during the first stage of its wetting by a sodium polyphosphate glass ( see fig 1).

The figure on the left shows in $\mathrm{X}$ the beginning of wettability phenomenon, $\mathrm{Y}$ for the initial glass drop, and $\mathrm{Z}$ the alumina . On right, EDS study of $\mathrm{X}$ part gives the composition of this glass.
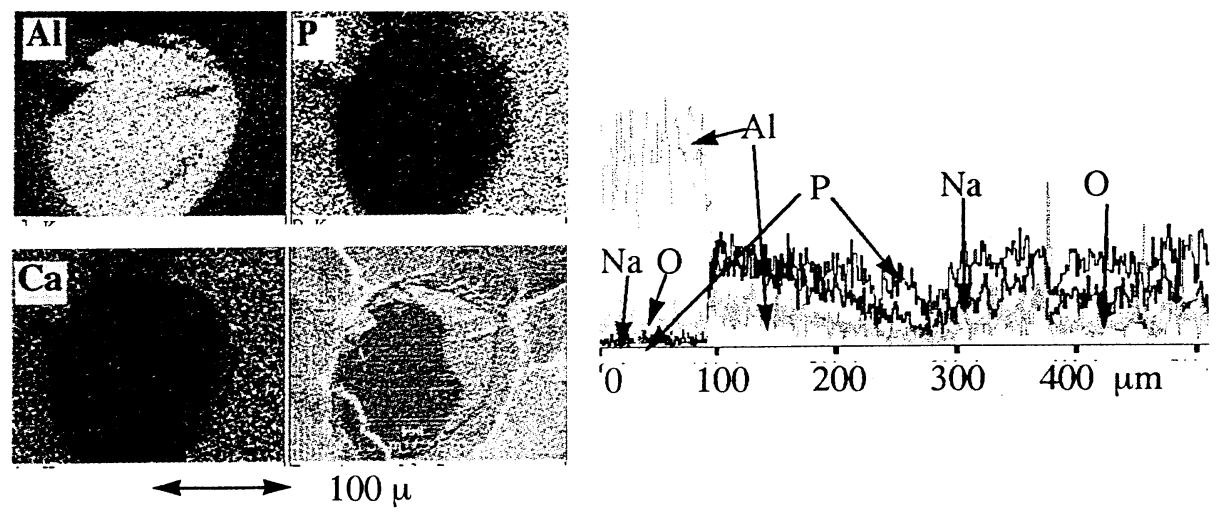

FIGURE 4. On left, a SEM with elements maping of sapphire fibers in a calcium phosphate glass matrix after fracture. We have a non diffusion of aluminium in the glass and in the same way a non diffusion of phosphorus and calcium in alumina.

On right an EDS profil of interface between fused alumina (on left) and sodium polyphosphate glass (on right) shows also a non diffusion phenomenon.

On the other hand, for all experimentions with several kinds of non active alumina and several kinds of polyphosphate glasses in the $\mathrm{Na}_{2} \mathrm{O}-\mathrm{CaO}-\mathrm{P}_{2} \mathrm{O}_{5}$ system, we have not detected ( by a SEM, with EDS studies) an important diffusion phenomenom of elements of the glasses in alumina and aluminium in the glasses. ( fig4) 


\section{DISCUSSION}

The formation of outgrowth structures may therefore be explained by the presence of a mixing of crystalline phases associated with glass as binding to increase the cohesion of the bubble of water gas, and may initially suggest us an important part of water in the wettability mechanism. In fact, the residual glass in the original glass bulk is partially hydrolized. We obtain more short species and the surface tension of glass may also increase ${ }^{3}$, but on the other hand the little species presence, may be explained by an exhaust $\mathrm{P}_{2} \mathrm{O}_{5}$ ( see equation 1). This exhaust increases with the chains length, and ultra phosphate formation, and the aluminium presence ${ }^{14}$.

To characterize this second hypothesis, we have placed samples of alumina near melted polyphosphate glasses at a temperature above their melting point. By SEM and ED S, we have charaterized the formation of a layer of aluminium phopshate, on alumina bulk without the sodium or calcium elements present in the glass fig (5). This result confirms an exhaust of reactive $\mathrm{P}_{2} \mathrm{O}_{5}$ from melted glasses, that reacts with alumina.
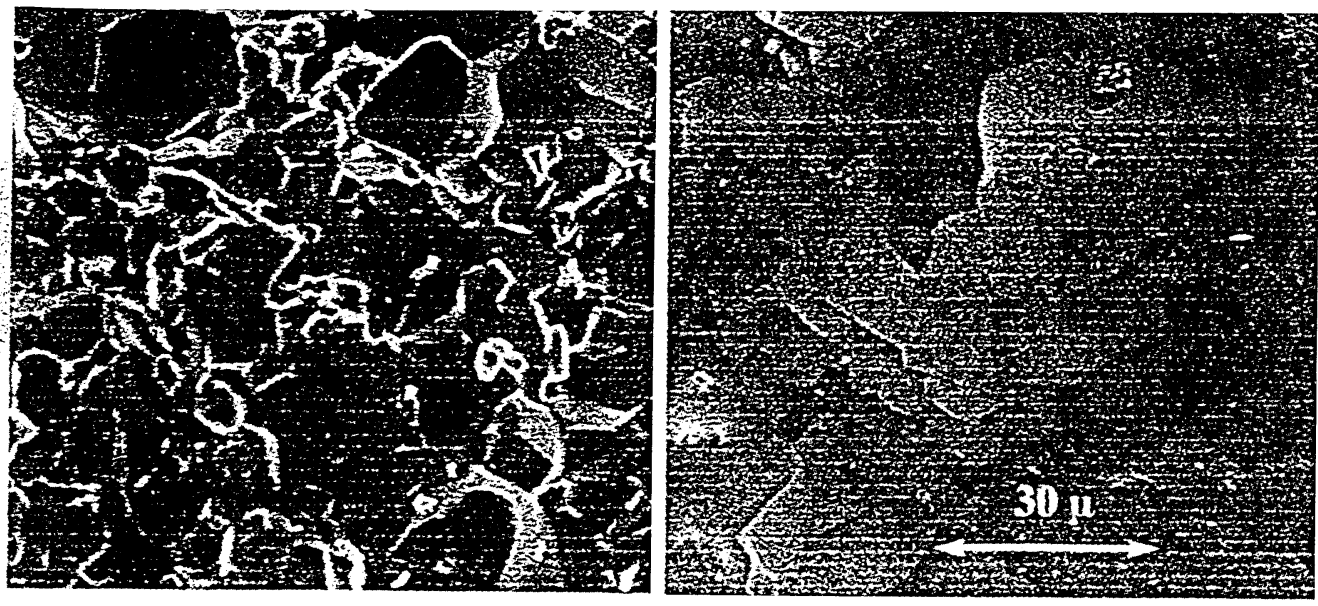

FIGURE 5. Behaviour of a surface of sintered alumina before and after exposure to phosphorus pentoxide exhaust from melted polyphopshate glass. Left before, right after.

If, finally, we compare the wettability power of polyphosphate glasses with an original substrate of alumina and the same substrate heated near polyphosphate glasses near their melting point, an important increase of the wettability phenomenon with the last substrate is to be observed. 


\section{CONCLUSION}

Our results show

- The important wettability of alumina by polyphosphate glasses in the $\mathrm{CaO}-\mathrm{Na}_{2} \mathrm{O}$ $\mathrm{P}_{2} \mathrm{O}_{5}$ system may be principally explained by an initial reaction between alumina and $\mathrm{P}_{2} \mathrm{O}_{5}$ which comes from the glass bulk in high temperature.

- The importance of the formulation of glasses which may be near to ultraphosphate stucture. Therefore, in a choice of phosphate glass for an aid of sintering of on active alumina, we may to add a new parameter such as the exhaust $\mathrm{P}_{2} \mathrm{O}_{5}$ power of polyphosphate glasses.

- The difference between polyphosphate glasses coming from a soft chemistry route as an aid for sintering aid for alumina based materials, towards the high temperature route for obtention of glasses. The second route may decrease the reactivity by $\mathrm{P}-\mathrm{OH}$ groups and increase the reactivity by $\mathrm{P}_{2} \mathrm{O}_{5}$ exhaust.

\section{REFERENCES}

[1] R.C. Ropp, Inorganic polymeric glasses ( Elsevier Amsterdam ) (1992)

[2] S.I. Berul, N.I. Grishina, Russ. J. Inorg. Chem. 18 (9), 1334 (1973)

[3] J.R. Van Wazer, Phosphorus and its compounds Vol 1 Interscience New York (1966)

[4] L. Montagne, P. Vast, G. Palavit, C.Plard, C.Oberlin; Matériaux et Techniques 7-8, 3,(1991)

[5] M. Draoui, P. Vast, G. Palavit, Rev. Chim. Miné, 22 256, (1985)

[6] B. Deffontaines, P. Vast, M. Deffontaines, Silicates Industrielles 3-4 145, (1994)

[7] P. Vast, F. Barbieux, F. Gomez, Verre 2-3 , 3, (1996)

[8] L. Montagne, P. Vast, G. Palavit, Thermochimica Acta 204, 61, (1994)

[9] S.I. Berul, N.K. Voskresenskaya, Russ. J. Inorg. Chem. 13, 218, (1968)

[10] L. Montagne Thesis University of Sciences et Techniques of Lille (1991)

[11] B. Deffontaines Thesis University of Sciences et Techniques of Lille (1992)

[12] M. Dhamelincourt, F. Alleene, O. Luczak, D. Ionescu, P. Vast, Proceeding of XV $\underline{\text { th }}$ International Conference of Raman spectroscopy Pittsburg (1996)

[13] F. Gomez, P. Vast, Ph.Llevellyn, F. Rouquerol, J. Thermal Analysis 49, 117, (1997)

[14] R.K. Brow , R.J. Kirkpatrick, G.L. Turner, J. Am. Ceram. Soc. 73-8, 919, (1990)

[15] R.K. Brow ,J. Am. Ceram. Soc. 76-4 , 913, (1993) 